This item was submitted to Loughborough's Research Repository by the author.

Items in Figshare are protected by copyright, with all rights reserved, unless otherwise indicated.

\title{
Conversational practices promoting a discourse of agency for adults with intellectual disabilities
}

PLEASE CITE THE PUBLISHED VERSION

PUBLISHER

SAGE Publications

VERSION

AM (Accepted Manuscript)

\section{PUBLISHER STATEMENT}

This work is made available according to the conditions of the Creative Commons Attribution-NonCommercialNoDerivatives 4.0 International (CC BY-NC-ND 4.0) licence. Full details of this licence are available at: https://creativecommons.org/licenses/by-nc-nd/4.0/

\section{LICENCE}

CC BY-NC-ND 4.0

\section{REPOSITORY RECORD}

Antaki, Charles, and Rebecca J. Crompton. 2019. "Conversational Practices Promoting a Discourse of Agency for Adults with Intellectual Disabilities”. figshare. https://hdl.handle.net/2134/17588. 
Paper for DISCOURSE \& SOCIETY

ACCEPTED VERSION, 20TH APRIL 2015

Conversational practices promoting a discourse of agency for adults with intellectual disabilities

Charles Antaki*

Dept of Social Sciences

Loughborough University

Loughborough

LE11 3TU

c.antaki@lboro.ac.uk

Rebecca J. Crompton

Limehurst Academy

Bridge Street

Loughborough

LE11 1NH

r.j.crompton-10@alumni.lboro.ac.uk

*corresponding author

SHORT TITLE: Discourses of agency 


\section{Abstract}

In a qualitative study of 50 hours of videotapes of interactions between staff and adults with intellectual disabilities, in two different service environments, we identified conversational practices that arguably promoted - or failed to promote - a discourse of service-users' personal agency in how they carried out everyday activities. Staff could treat the service user as an autonomous, self-directed social individual a) by casting the activity in which they were engaged as being located in a meaningful overall framework; b) by designing their turns at talk as suggestions and requests for the service-user to follow as a matter of choice; and c) by implying a joint purpose shared between service-user and a larger group in which he or she was a stake-holder. We discuss these findings in the light of recent developments in the drive to empower service-users who have intellectual disabilities.

Keywords

Intellectual disability, discourse, empowerment, agency, personal control, conversation, questions, activities 
Over the last twenty years there has been a growth in the determination that service users with intellectual disabilities be given more control over their lives. The psychological establishment (e.g. the British Psychological Society Professional Affairs Board, 2000; the American Psychological Association Disabilities Office Mission, n.d), campaigning groups (e.g. the British Institute of Learning Disabilities, 2009; MENCAP, n.d.) and government and international agencies (e.g. the UK Department of Health, 2001, 2009; the United Nations Convention on the Rights of Persons with Disabilities, 2006) have converged on the view that legal, welfare and mental-health provisions require strengthening to ensure that people with intellectual disabilities be allowed to lead more independent lives. Indeed, in the UK, the Mental Capacity Act of 2005 protects the rights of individuals to make decsions when they have the capacity; and makes explicit the need to guard against removing that right when capacity might be difficult to ascertain. Nevertheless, the battle for independence and equal treatment is complex (Power, 2011) and far from won (Disability Rights Commission 2007).

Below the level of statute and policy regulation, a common discourse shared by many campaigners and proponents of change is one of individual, personal agency. That is, they recommend that service-providers who support people with ID try to foster their sense of control over their environment. This core concept is referred to by a variety of terms: "agency" (e.g. Rapley, 2004), "personal and social responsibility" (e.g. Tassé et al, 2012) or "selfdetermination" (e.g., Wehmeyer and Bolding, 2001), and is enshrined in such policy-driven initiatives as "Person-Centered Planning" (Routledge \& Sanderson, 2001; and for a collection of views, see Cambridge and Carnaby, 2005). In the constituent parts of the UK, governments have developed a variety of schemes to allow people with ID (among others who are entitled to social care) to tailor support to their own personal needs, including employing their own support staff. All these terms share the idea of promoting the service-user's sense of control over, and choice in, their everyday lives (unrealistic as some critics believe this to be; see, for example Johnson 2013 on the UN Convention on the Rights of Persons with Disabilities; and Shakespeare 2013, more generally). 
To cover the variety of ways of referring to the sense of control and choice, we shall use 'agency' as a convenient general term. As discursively-inclined commentators (e.g. Antaki et al, 2009; Rapley, 2004; Williams, 2011) have observed, the most visible manifestation of such agency or personal selfdetermination for adults with ID will be in their everyday interaction with support staff. It is in the details of such interaction that one may see the serviceuser take, or be granted, control of their actions. As these commentators point out, to exercise control and to be autonomous is inevitably a public and interactional event, requiring the exchange of talk between the individual and those around her or him (who may encourage or frustrate their initiatives). Finlay et al (2008) put it more strongly when they put the converse case, on the basis of their research, that "disempowerment and dependence happen in the routine matters of people's lives, and that power is exercised in the way people talk to each other " (2008, p 227).

Even if one was cautious about whether a service-user was actually autonomous or not, then, as Williams puts it: "it is not 'autonomy' itself which is in question, but the way in which the concept of autonomy is produced (or negated) through actual interactions" (Williams, 2010, p. 90). In other words, although it is hard to assess whether or not people with ID actually experience the sense of agency as a psychological state, one can certainly assess the way that the discourse of agency - the implication of powers, abilities and will - is visible in the way that people talk to them.

In this article we will focus on exactly how such exchanges of talk proceed. We will highlight the way that talk promotes a discourse of agency by comparing verbal practices in two services which provide different kinds of support to adults with intellectual impairment. In one case, the adults are supported at home by care-staff who have minimal training in communication skills; in the other, the adults attend a 'horticulture therapy' establishment which offers guided work around a horticultural centre, supervised by therapists and volunteers whose training includes communication skills. The comparison is, we 
think, telling; not because we want to pass judgment what these places do (they are set up to provide quite different services, and resist evaluation on the same criteria), but rather because their different ways of engaging with their clients throws so clearly into relief what it means to promote agency through talk.

Both services, like others of their kind, do want to promote agency and autonomy, as enshrined in their 'mission statements'. Although we cannot offer verbatim quotation for reasons of anonymity, we can say that a concern for service users' personal independence is salient in the prospectuses of both the Local Authority Trust which runs the residential service, and the charity which runs the horticultural therapy centre. However, suggestive as they might be, such abstract mission statements need to be instantiated in the day-to-day operation of the service. Here again, both services seem, on the face of it, to offer ample opportunities for the staff to engage with their clients in a way that would encourage self-determination. In both the residential home and the garden centre, staff engage their clients in a variety of verbal and physical tasks, and it is in the power of the staff to portray the service-user's engagement in such activities as being willed, conscious and goal-oriented. Let us see how they do so.

\section{Data and analysis}

Recordings The data come from video recordings made at two services at various times over the years 2008-2012, both in the south of England. One is a residential service, in which five adult men with IDs are supported in their shared home by a roster of support workers. The other is a "therapeutic horticulture" charity which offers supervised gardening activities to members of vulnerable groups, including adults with IDs (for the use of garden spaces for therapeutic purposes, see Simson and Straus, 2003; for a discussion of such services in the UK see Sempik et al, 2005). Some 50 hours of video were shot at 
these sites, on and off, over a period of two years (residential service) and four years (garden service) ${ }^{1}$.

In the residential home, the staff's duties were to supervise and help plan residents' daily activities such as cooking, shopping, social excursions and so on, to oversee the functioning of their general living arrangements, and to offer personal social support by encouraging conversation and association. In the gardening centre, staff were trained horticultural therapists who supervised and instructed service-users in a variety of simple gardening jobs (e.g. weeding, filling pots with compost, identifying plants and so on) with the aim of increasing their self-confidence, independence and social functioning.

Ethics Formal ethical oversight was provided by [anonymised] University, and by each of the centres involved, and written informed consent was solicited from staff and service users before filming began. All staff, and most service users, gave permission; no recordings were made of those who did not. All names and identifying details reproduced here in the transcripts have been changed.

Analysis We will report three pairs of comparisons that highlight ways in which members of staff talk to service-users. In each pair of cases, we have taken care to study activities that are more or less comparable in what they require of the service user in terms of their immediacy, difficulty, scope and so on. The aim is to see how a member of staff, supporting a person with intellectual disability, might work to establish an environment which treats the person as having personal agency.

Giving a meaningful framework, providing for voluntary execution, and implying joint purpose.

${ }^{1}$ For more detail on the environment of these services, and our engagement with them, see Antaki, Finlay, Walton, and Sempik (2015). We are grateful to Chris Walton and Joe Sempik for their work in making recordings in the residential service and the garden service, respectively. 
By inspection of the data we identified three things that the staff member could do to enhance the agency of the service-user's involvement: put the activity into a meaningful overall framework; design at least some of their turns at talk as suggestions and requests to be followed voluntarily; and imply a joint investment in the performance of the task or its outcome. This was done to different degrees in the two services we studied. We do not want to say that positive discourses were never used by support staff in the residential service, or were always used by the therapists in the garden service; but, in order to provide vivid examples of the use and non-use of such ways of talking, we have chosen pairs of episodes where the distinction is clear.

\section{Activity 1: Locating a target}

Our first examination of ways of talking is in a comparison of the service users' engagement in a task requiring them to identify or locate a target area or object.

a) Example 1. Garden Therapy (VD19 Mar pm min. 0.40). Geraniums Sophie is a horticultural therapist, and Frank is a service-user with an intellectual disability. They are in a small group, outdoors. [NB talk between participants not involved in this particular activity has been left out of the transcript].

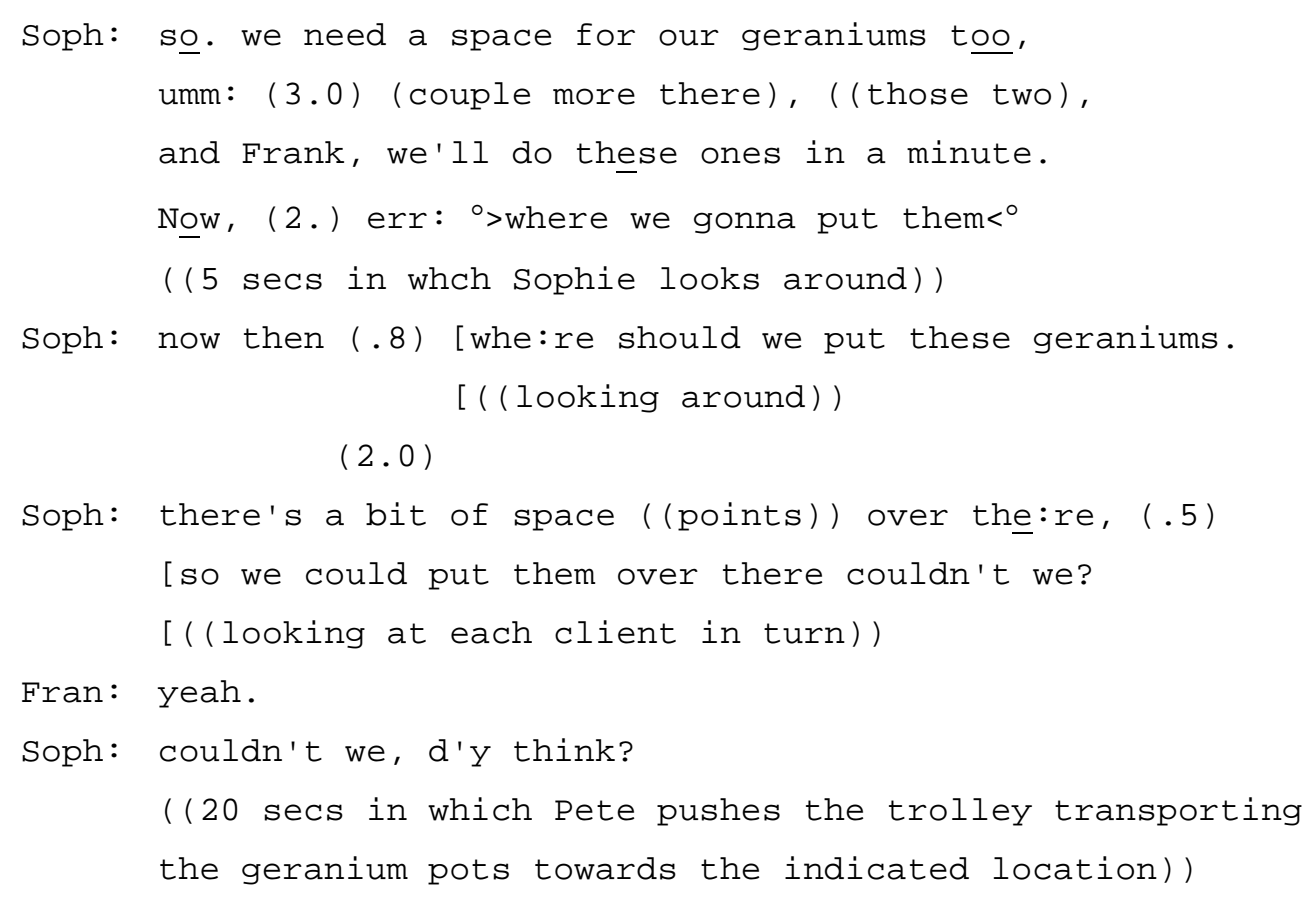




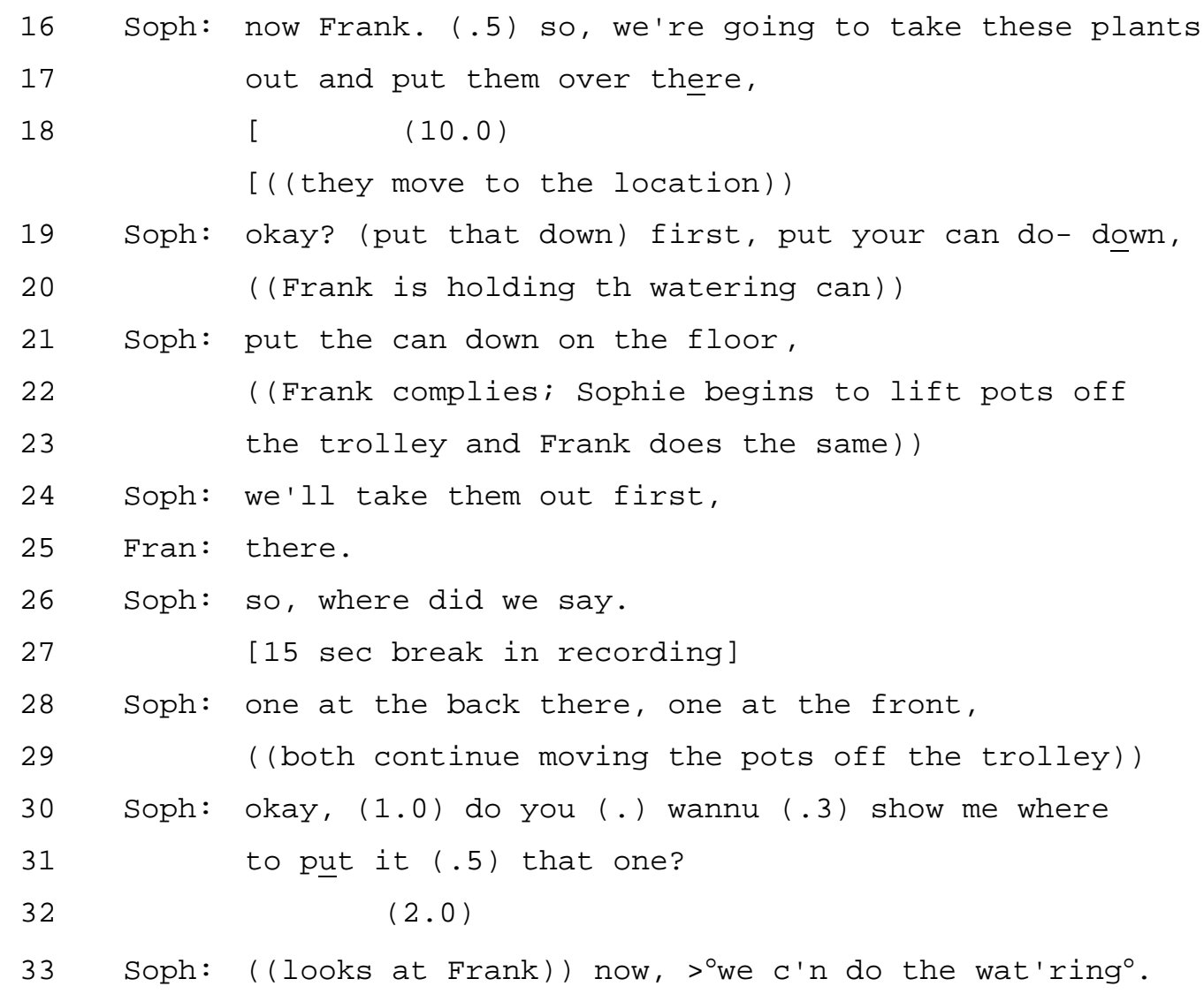

Frank's task would be efficiently accomplished (in a physical sense) were Sophie to simply to instruct him to place the pots in a given location. However, notice three things that Sophie does to enhance the agency of his involvement: she gives an initial, meaningful overall framework for the activity; she designs at least some of her turns at talk as suggestions and requests; and she uses the inclusive "we" in her instructions. These are the dimesnions we shall find in all the subsequent data; let us consider them in detail.

a) Putting the activity in a framework. The therapist advertises the upcoming activity in a series of turns which are hearable as both musing out loud for the benefit of the group (lines 4-5) and a targeted set of enquiries specifying the nature of the task at hand. The objectives are cast as ones for the group as a whole: "we need a space for the geraniums" (line 3) "where we gonna put them" and explicitly to the group "Now then. where should we put these geraniums?" lines 6-7, said while looking around the group at eye level). This kind of proposed introductory framework, although it is "instructional", as Williams 
notes (Williams, 2011, p 33) does allow Frank's activities within the upcoming timeframe to be understood as a means to achieve a given objective.

b) Using requests and suggestions. The therapist uses a mix of directives (for a recent an overview of the study of directives in interaction, see Stevanovic and Svennevig, 2015). At the most unilateral, she does use imperatives at one point during the episode: these seem to be occasioned by needing to clear away something that would impede the service user from carrying out the main task (lines 25-29: Frank needs to put down the watering can in order to move the plants). However, most of her talk is cast as suggestions and proposals. In lines 910 she indicates a given location, making it available to all the group as a candidate, and follows up with a proposition (so we could put them over there couldn't we?), which she issues again as couldn't we, d'y think?, possibly as means of checking Frank's ambiguous agreement. At line 30 she explicitly defers to Frank in asking do you want to show me where to put ... that one? . Such deference, and the orientation to Frank's contingencies (Curl and Drew, 2008) casts him as having some control over proceedings.

c) Joint purpose. At nine points in this short episode the therapist invokes the group as a whole, or the pair comprising her and Frank, by the use of we. One will do as an illustrative example of the implication of joint purpose: now Frank. so, we're going to take these plants out and put them over there. The service user is treated as having a stake in the matter: the activity is cast as a shared one, involving the service-user in whatever intentions and purposes that the therapist could be considered to have in performing it.

In the next, and contrasting, example, we turn to the residential service. The interaction is a small excerpt from a scene, in which Tim (a support worker) is supporting Alec (a service user) in cooking. The focus is on the location, selection and acquisition of one piece of equipment, a particular saucepan. This task allows us to see the opportunities given for Tim to use a way of talking about what Alec is doing that promotes his agency, in deciding what saucepan to select, locating it, and putting it to use. 
Example 2. Residence (VD08 min 22:09) Saucepan

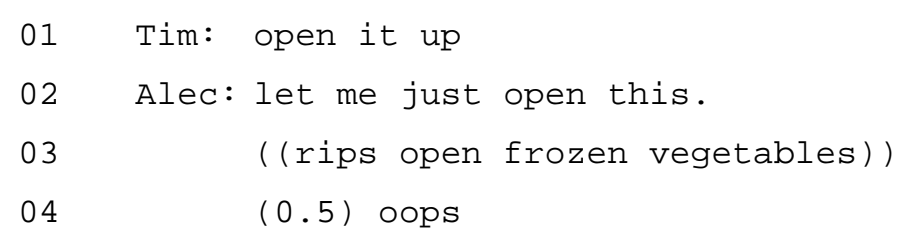

$05 \quad$ (1)

06 Tim: right (that's done) put them in there,

07 ((Alec tries to pour vegetables out of packet))

08 Alec: they won't come out they won't come out.

09 ((Tim also grasps packet and shakes, vegetables come

10 out ))

11 (2)

12 Tim: right (.) now get another small saucepan,

$13 \quad(1.5)$

14 Tim: get the small saucepan as well,

15 ((Tim points to cupboard))

16 Alec: small one

17 ((Alec opens cupboard and gets saucepan out))

18 Tim: no not that one it's too small (๑.5) that one there

19 ((Tim points into the cupboard))

20 Tim: no no that one,

21 ((pots clashing))

22 Tim: that one there,

23 (1)

24 ((Tim moves finger closer to cupboard))

25 Tim: push that one aside (1) put that one there back where

26 it was, push that one away (.) now tha-get that one out.

$27 \quad(2.5)$

28 Tim: now now open this $(0.5)$ put it there (.) open this,

29 scissors

30 Alec: scissors

We can see this episode differs from the one in the garden service (Example 1) in the way agency is attributed. When we look for thestaff member's provision of a framework, his use of requests and his establishment of a joint purpose, all seem absent. 
a) Not putting the activity in a framework. Lines 1-11 in the extract show that the initial imperative on line 12 is not preceded by any elaboration of the task's context. This arguably compromises Alec's ability to choose the right saucepan, as we cannot assume that he knows what it is going to be used for, and so can't tell which one will be appropriate. His task is not treated as being instrumental in a larger, meaningful activity; it is an isolated chore.

b) Not using requests and suggestions. Following the initial instruction is a series of imperatives (Craven and Potter, 2010), often repeated (for example push that one aside... put that one there back where it was, push that one away). Physically Tim mirrors his verbal style by pointing into the cupboard throughout most of the interaction, even though it becomes clear that this does not seem to be a successful strategy for helping Alec. Imperatives, as Craven and Potter argue, allow for no sense that the recipient has a choice; compare, for example, the garden therapist's use of such requests as do you want to show me where to put ... that one.

c) No joint purpose. In this example joint purpose is notable for its absence. The pronoun 'we', for example, is not present at all during this extract. Tim consistently fails to use language implying collaboration in, or a given overarching purpose to, the search for a saucepan. There is no sense that Alec is engaged in a task in which co-operation, as opposed to compliance, is possible. Unlike the episode in the garden service, the staff member here uses no descriptions of the task that imply that the service-user is a stakeholder in the activity he is carrying out.

This first pair of extracts, then, comparing how staff in different services manage 'looking for something', demonstrates clearly how agency can be attributed and encouraged through use of language. Both service users are ultimately successful in 'completing' their tasks, but the implication of their agency is markedly different. In Example one we are able to see staff construct a clear framework, present the activity as having as a joint focus, and treating the service user as one 
who may choose to follow suggestions. In contrast, Example two contains none of these features.

\section{Activity 2: Planning the next step in an overall task}

In our second pair of activities to compare, the common feature is that the staff member is dealing with a client who is mid-way through a multi-component task that requires planning. In the garden service, the overall task is to go around identifying a number of items listed on a printed check-list; in the residential service, it is setting the table for a meal. In both cases, a hitch develops.

Example 3. Vid 0141, min 1. A-Z of things in the garden

Two garden therapists (Bill and Janet) are guiding service-user Tom in planning the next stage of the task he is engaged with, namely filling in the name of a plant/object, seen around the garden, for each letter on his clipboard.

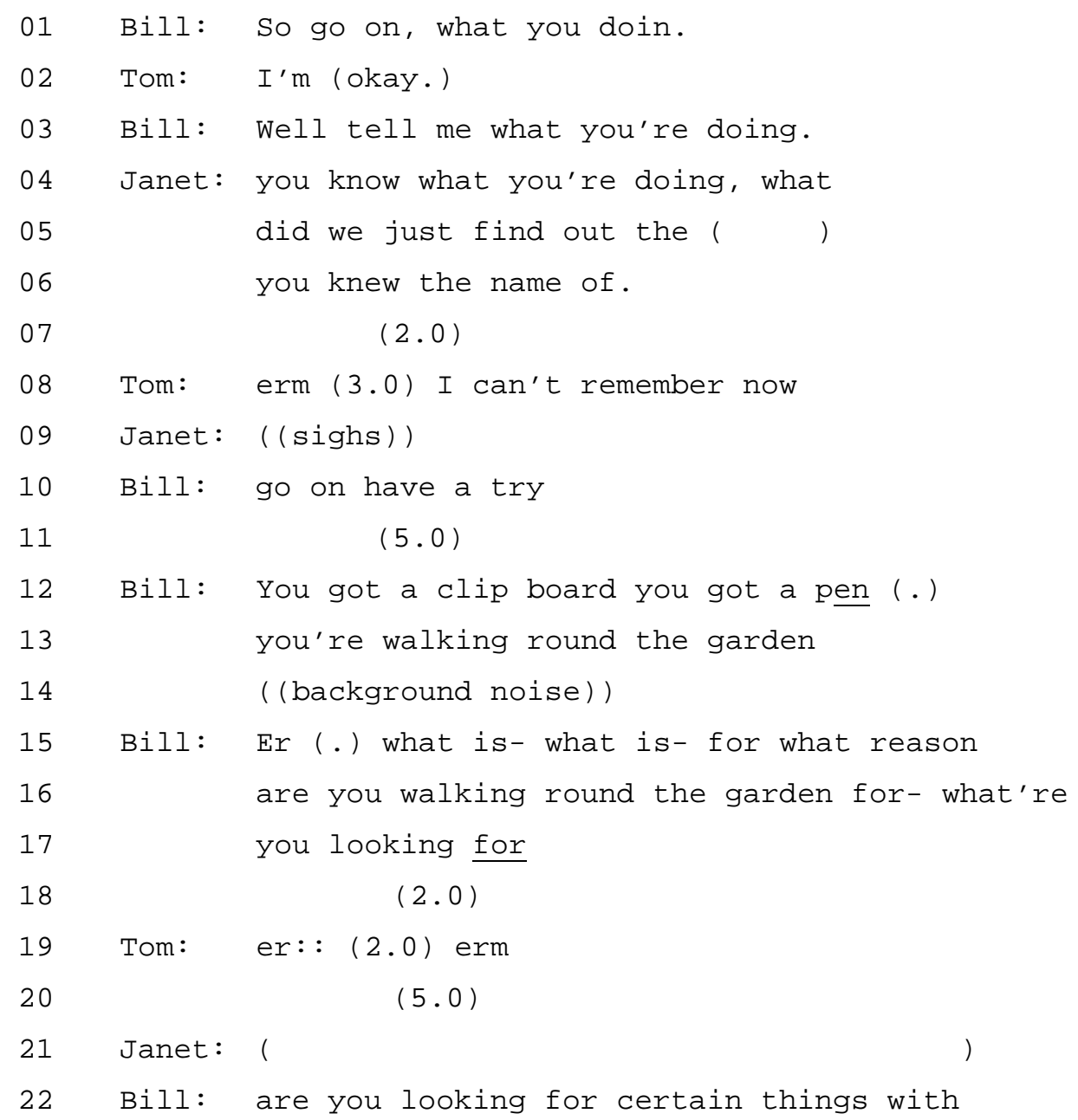




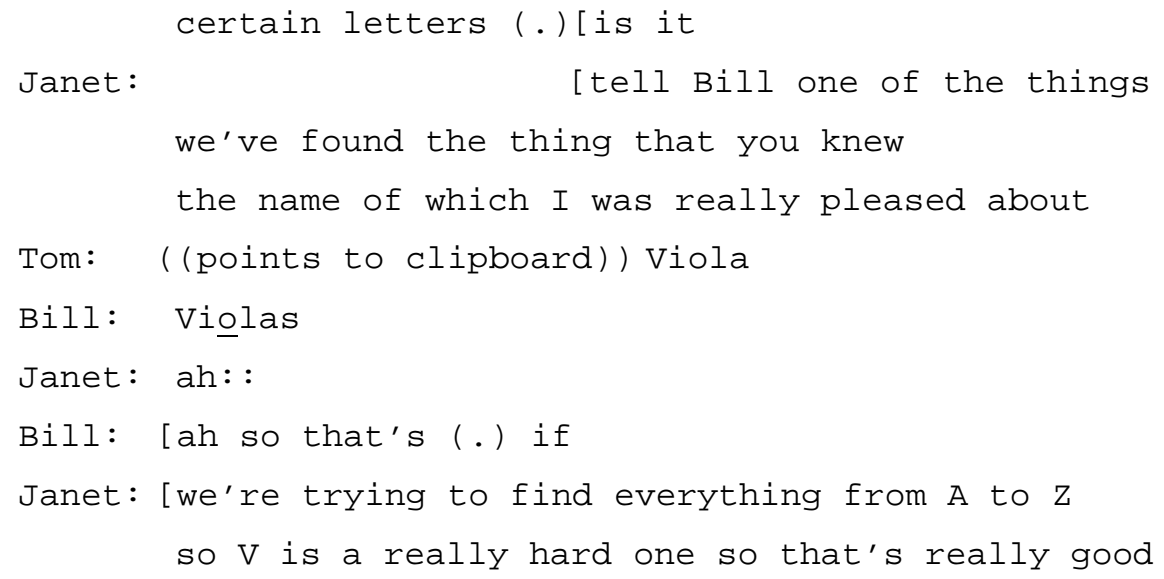

In this extract we see good examples of the kind of agentive discourse that the staff use to prompt the service user to reflect on his engagement with the task he is planning.

a. Putting the activity in a framework. The larger frame of the activity is Tom's search for items around the garden. His replies at line 2 ("I'm okay") and at line 8 ("I can't remember") might suggest his disengagement from whatever project was in hand. A less assiduous staff member could let it go, or a more directive one simply instruct Tom as to what he was meant to do. Note, however, how Bill uses hints and references (e.g. lines 12-14, "you got a clipboard, you got a pen, you're walking round the garden") which place Tom into a framework of something which he knows about and makes sense as a fulfillable project. Tom is prompted to remember what he is using, and, by lines 22-23, all but explicitly given the aim of his task. All these prompts and hints treat Tom as remembering what he was doing, and why he was dong it. In other words, it promotes the sense of him being knowledgeable about the reasons for his actions (even though he may have temporarily forgotten them).

b. Using requests and suggestions. Janet's "you know what you were doing" (line 4) and Bill's "have a try" (line 10) give the tone of the staff's dealings with the service user here. They use suggestions, requests and hints as prompts; the common thread is that all these imply that Tom knew what he was doing. It is a matter not of instructing him, but of reminding him. This assumption of his having some plan of action in mid is clearest at lines 15-17, when Bill explicitly 
attributes him with having a reason for what he's up to. Test questions these may be; but it is Tom who is treated as being competent to answer - who is further up the "knowledge hierarchy" in the interaction (Heritage 2012).

c. Joint purpose. Although presumably the idea of a checklist to be ticked off came from the garden staff, Tom is treated as being involved in a larger joint enterprise than merely performing an allotted, individualised task. This is clearest in lines 24-14 and 31-32, when Janet explicitly casts the project as one involving Tom with other people. The "we" she uses is ambiguous as a referent (for a discussion of pronominal choice with reference to social relations, see, for example Mühlhauser and Harré, 1990), but seems to imply she and Tom at the very least; so he is recruited into a working team, with a joint stake in the outcome of his actions.

Compare the garden staff's discourse with that of the residential support worker in this structurally similar episode. Here, service user Dom is in the middle of setting the table for lunch, and has reached the next stage - preparing the fruit drinks in the kitchen to take out to the table. He has, so far, poured syrup into three jugs and topped them up with water, somewhat unequally. Staff member Tim appears.

Example 4. VD10 Jugs [NB talk between participants not involved has been left out of the transcript].

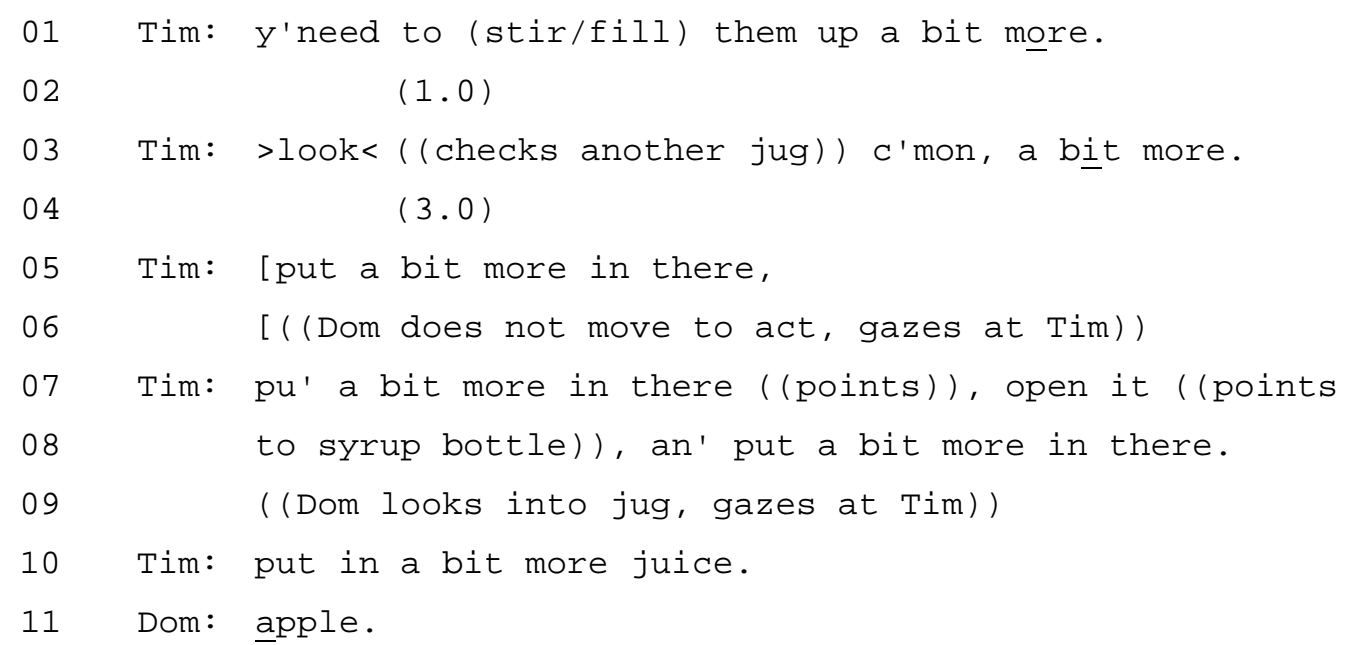




\section{a) Not putting the activity in a framework.}

As with Example 3, the service-user is in the middle of a larger sequence of actions (here, preparing the table for lunch). But at no point during this episode does the staff member treat the service-user as if he were engaged in such a larger, planned, sequence. At best one might say that this is taken for granted, but certainly it is not made explicit. Compare this with the efforts made by the garden staff, who make repeated reference to the overall activity that the service user is involved ("you got a clipboard, you got a pen, you're walking round the garden"). Here, the staff member Tim's point of engagement with resident Dom's activities is, if anything, an admonishment at a specific task poorly executed, with no reference to the overall sequence of actions in which it is embedded.

\section{b) Not using requests and suggestions.}

Having identified a possible mistake on the service-user's part, the staff member could use a discourse of responsibility and control in finding ways to encourage him to identify the problem, and remedy it himself. Instead, his first four turns are instructions, using six imperatives (lines 1, 3, 5, and 7-9). As Antaki and Kent (2012) observe, in using such directives, speakers "issue requests in formats that assume their complete entitlement to do so, and ... make no provision for contingencies that might hinder the client" (p 887). Again, compare this to the garden staff's use of hints, suggestions and prompts, which combine to treat the 
service-user as being able to identify and solve the planning problem that he's faced with.

\section{c) No joint purpose.}

Where Tim uses an instructional format, he might, as the garden staff did, have used a way of presenting the task as being a shred one, for the general good laying the table, or in this sub-activity, preparing the juice - for the benefit of Dom's fellow residents. This was manifestly absent. It would be hard, from this episode at least, to see Dom as having any stake in a joint enterprise; rather, he is treated as an executor of detailed instructions, without the larger, communityoriented end in sight.

\section{Activity 3. Resuming an activity}

Our last pair of comparisons is of the staff member requiring the service-user to resume an activity in the face of some resistance or reluctance. The first example below is from the garden, where a volunteer (May) is supporting a service user (Larry) in filling pots with compost.

Example 5 Garden Therapy (19 Mar pm min. 11.57) Stalk

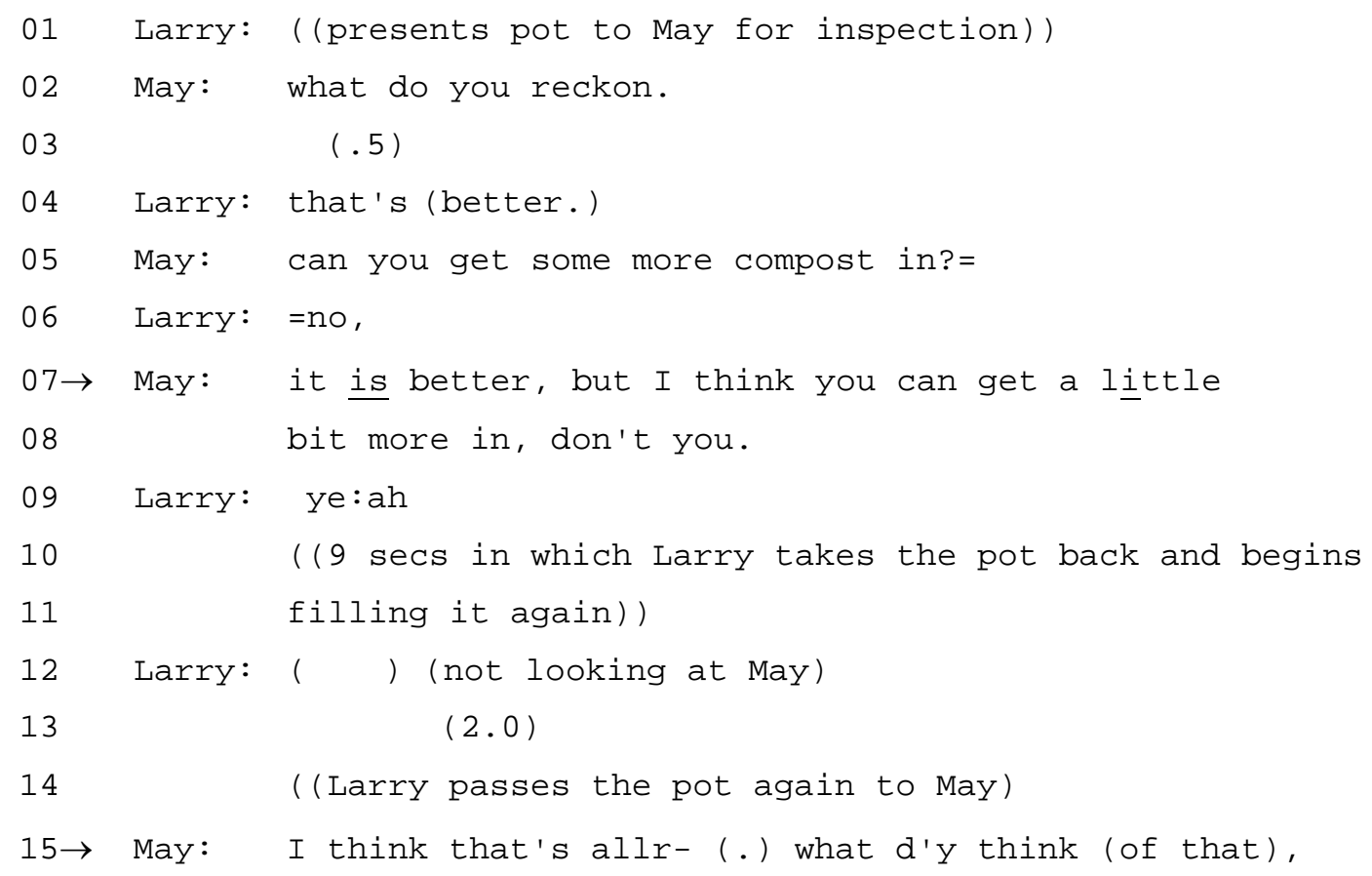




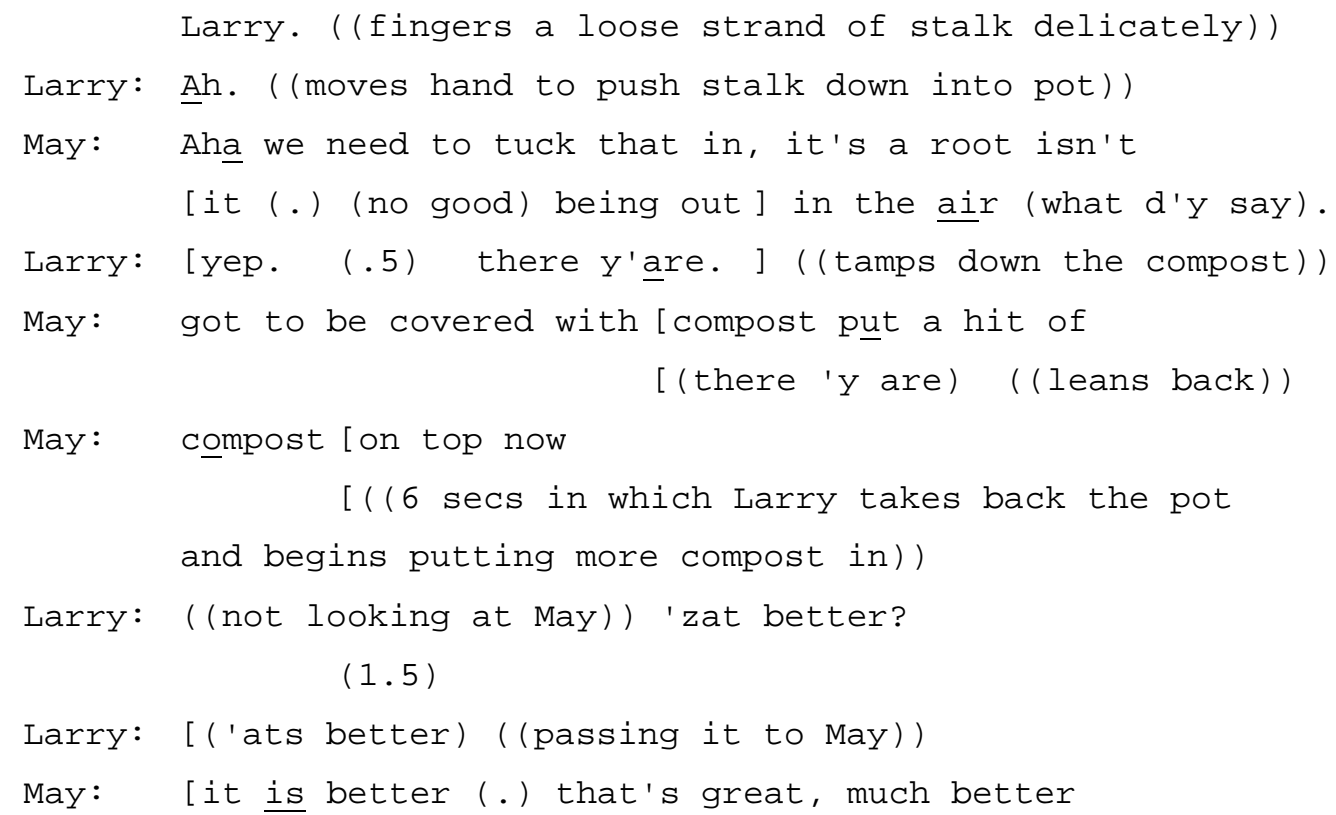

a) Putting the activity in a framework. The recording begins too late to capture the set-up of the task, but evidence from other similar episodes suggests that this pot-filling exercise is usually introduced with a brief explanation of the need to accommodate seedlings' expected growth.

b) Using requests and suggestions. Again we can see the staff member's orientation to the service-user's agency in the task in the way she designs her talk. At line 2 she invites the service-user himself to adjudicate on whether the task has been adequately completed or not, in a "test question" to which the answer would be no. In fact, he does not understand it this way, so May needs to clarify that more compost is wanted. Rather than do this by direct command, she concedes that the pot's level of compost is "better", but expresses her own view that more can be put in, ending with a tag question inviting Larry's confirmation. When Larry passes her the pot for re-inspection at line 15, May again finds occasion to withhold approval, but again refrains from direct instruction. Instead, she invites Larry to notice and evaluate a loose part of the plant. She explains that it's a root isn't it.. no good being out in the air, implying that it requires tamping down, and inviting him to contribute his own judgement - what d'you say. 
c) Joint purpose. At line 18 May explicitly casts the activity as being a joint one (we need to tuck that in) even though it is Larry who is doing the actual work with the compost. As noted in (b) above, she does this in an environment of explication of the task as a whole: she invites Larry to see why the current level of compost in the pot is inadequate as a matter of the ultimate fate of the plant in the open air.

Consider the last of our examples, where in the residential service a support worker (Kev) encounters a difficulty in engaging a resident (Henry) in resuming a task. This episode takes place during food preparation.

Example 6. Residence (VD 21 min 26:01) Award ceremony.

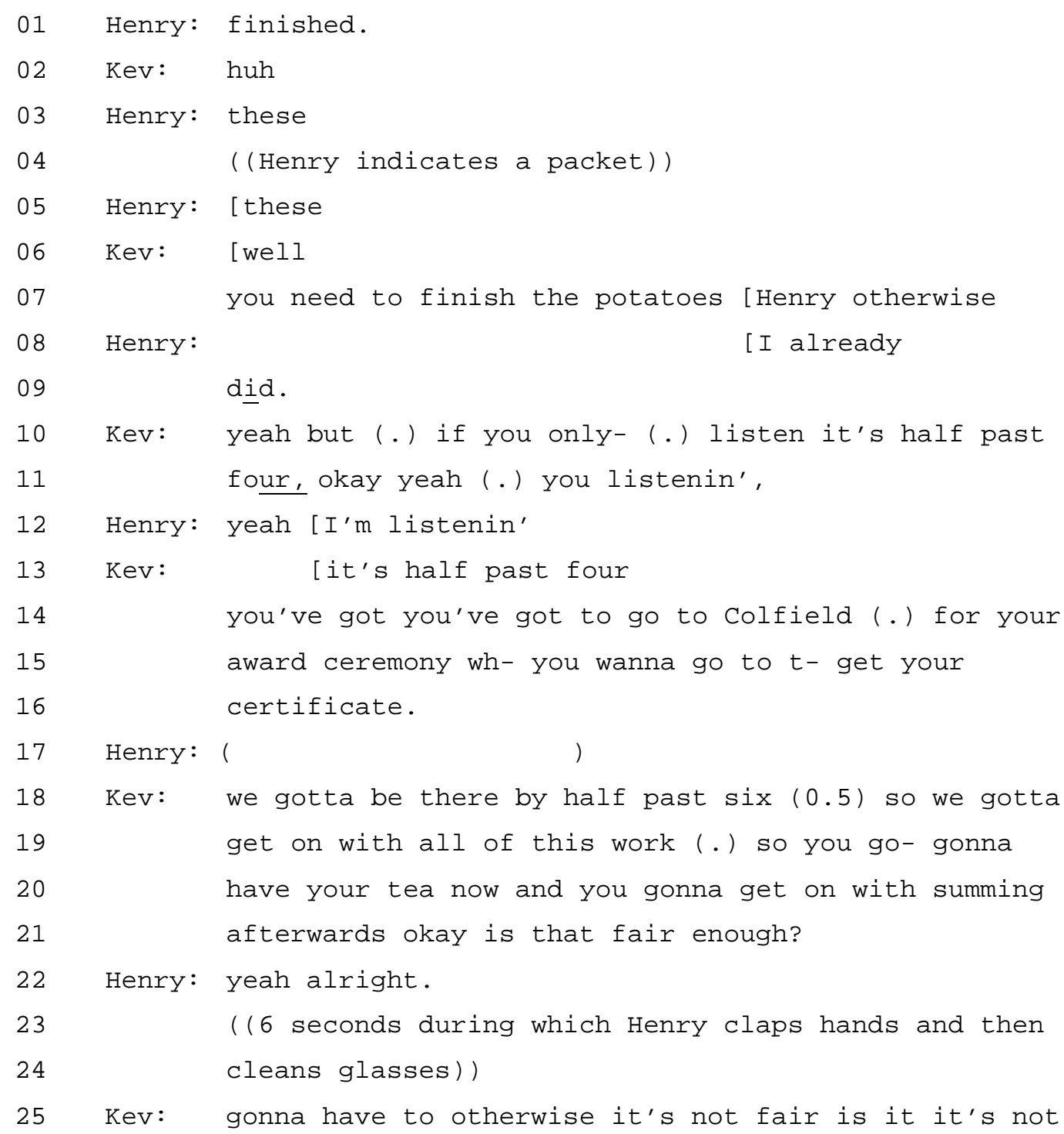




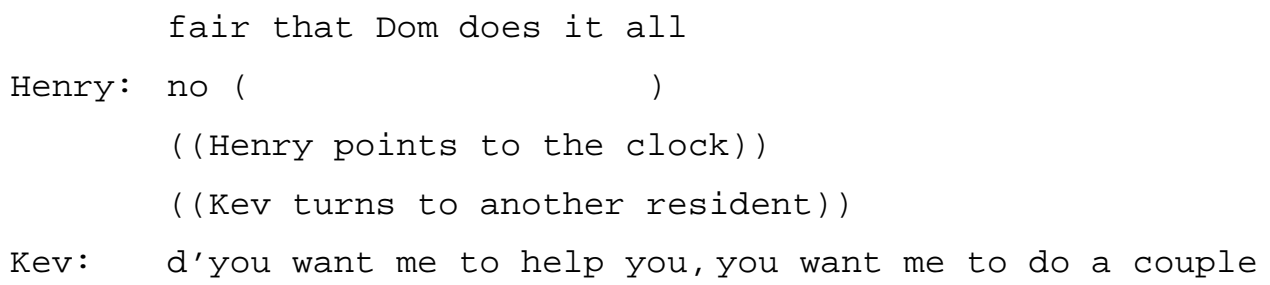

a) Not putting the activity in a framework. The support worker, Kev, does provide a framework, of a kind - but only after his initial instruction, issued as a modal declarative you need to finish the potatoes (line 7). Kev does then (lines 10 -21) explain why this must be done., but in a series of unilateral assertions in the format of modal declaratives: you've got to go to Colfield, you wanna get your certificate, we gotta be there by half past six. The conversation remains onesided; Kev does not provide for Henry joining the narrative. Moreover, the point in the sequence where this framework was offered is fundamentally different from its sequential location in our comparison Example 5. Here, the request, or command, is issued first. This defines the task before any framework or context is proposed, demonstrating that, rather than providing a sense of agency, decision and understanding, the purpose of this framework, when it comes is heard as being in the service of staff instructions.

b) Not using requests and suggestions. Kev fails to invite or prompt Henry to join the conversation, with two exceptions (lines 9 and 18) where he asks a simple yes-expecting question. However, there is one exception where we could construe that Kev attempts to involve Henry in decision making. On line 17-18 Kev asks "is that fair enough"; we can view this in two ways. As Kev does provide time for Henry to respond, we can assume that this is not rhetorical; it serves the purpose of softening his previous communications and allows Henry some autonomy in the choice it appears to present (see Williams, chapter 7, on such offers of autonomy). On the other hand, the actual question asked 'is that fair enough?' does not allow Henry to select an answer which involves choosing not to complete the task, only to judge whether or not it is a fair expectation. Generally, we would understand this question to be an opportunity to express refusal, however it is not clear that Henry can make a more complex 
conversational deduction and produce a more complex response in order to challenge Kev, even if we ignore difficulties with institutionalisation.

c) No joint purpose. Contrary to the previous example from the residence (Example 2) Kev uses direct personal pronouns throughout this excerpt and we can see the attribution this allows him to make, namely that the task is Henry's. However he fails to use you in any sense which provides a sense of agency to Henry, instead using it to frame imperatives and instructions- you gotta (line 15) and you gonna (line 16) - examples of what Curl and Drew (2005) call low orientation to the recipient's contingencies. This way of talking to him compromises the image of Henry's having the capacity to collaborate in making a choice in which he has an independent stake.

\section{Discussion}

The aim of this article was to explore Williams' observation that "autonomy ... depends on the ebb and flow of talk and the small details in interaction" (Williams, 2010, p 105), and Antaki et al's (2008, p 264) claim that "analysis of real-time interactions reveals the complexities of offering choice". We wanted to identify, in the exact details of conversational interaction, ways in which staff could promote or discourage a discourse of agency in a service-user's engagement in an everyday activity. This to say, engaging with them in such a way as to promote the idea that the service user had an interest in, planned for, had control over, and independently carried out such mundane things as moving plant pots, fetching a cooking pan, and so on. We chose to study two serviceproviders whose mission statements included a commitment to promoting personal empowerment. We saw that this was fulfilled in very different ways, for a variety of insitutional reasons, about which we might speculate very briefly here: the contrast in the training of the staff, the more routine nature of the residential activities, the greater time available to the garden service, and so on. But for our purposes, the difference threw into relief three dimensions along 
which we could lay out their practices.- meaningfulness, autonomy and stakeholding.

Giving the service user a framework for the upcoming activity, for example by explaining why seedlings need to be re-potted, treats them as having some meaningful overarching, purposive, end-oriented task that informs their actions. A service user not given the benefit of such a framework is being cast as someone not likely to understand either the ostensible aims or implications of their actions, and must wait for instruction.

In terms of treating the service-user as an autonomous agent, a prominent thread running through the staff's exchanges is what Curl and Drew (2008), in a highly influential study of requests in interaction, call the entitlement of the requester and their orientation to the contingencies facing the person of whom they were making their request. The imperatives that staff member used in examples 2 and 4 (for example, push that one aside ... put that one there back where it was, push that one away) made no concession to the contingencies facing the service user (in this case, the awkward placing of items in the cupboard, the lack of a unique description to work with, the fact that he had to bend double, and so on), and presumed the staff member's complete entitlement to issue such commands without negotiation. Examples 1 and 3, on the other hand, although they did include imperatives, showed that one could acknowledge the serviceuser's difficulties and claim less unilateral entitlement, as in there's a bit of space over there, ... so we could put them over there couldn't we?.

With regard to stake-holding, any task could be introduced so as to emphasise its shared nature - for example when, in Example 1, the staff member introduces the activity with we so - we need a space for our geraniums. A discourse of agency casts the service users as being involved in a shared purpose, on a shared footing. with a stake in the task's outcome. Compare the converse in Example 1, where the staff member provides nothing to suggest that the search for the saucepan was a joint task, still less that it was on a shared footing: this is not likely to engender a sense of control and agency. 
Williams observes that "[i]deas of incompetence are very pervasive... [and form] a 'naturalised' discourse" (Williams, 2011 p. 6). Taken together, the three themes we have identified seem to capture three dimensions along which that discourse emerges in talk. No doubt the different kinds of training in the two serviceproviders plays a part in the contrast in the data, as does the nature of the services they provide. But it is possible to see that even when the staff member is under the institutional constraints of a poorly-resourced service (as residential support tends to be), appropriate training in communication skills might help in transforming discouragement into encouragement, and help foster an environment of control and choice among service users. 
References

American Psychological Association (no date) Disabilities Office Mission http://apa.org/pi/disability/about/index.aspx [accessed 23rd March 2015]

Antaki, C, Finlay, W M L, and Walton, C. (2009) Choice for people with an intellectual impairment in official discourse and in practice. Journal of Policy and Practice in Intellectual Disabilities, 6(4) 260-266

Antaki, C, Finlay, WML, Walton, C. and Sempik, J (forthcoming 2015)

Communicative practices in staff support of adults with intellectual disabilities. In M. O’Reilly and J. Lester (eds.) The Palgrave Handbook of Mental Health. Basingstoke: Palgrave pp xx-xx

Antaki, C. and Kent, A. (2012) Telling people what to do (and, sometimes, why): contingency, entitlement and explanation in staff requests to adults with intellectual impairments. Journal of Pragmatics, 44, 876-889

British Institute of Learning Disabilities (2009) Factsheet: Advocacy. Birmingham: BILD

Cambridge, P and Carnaby, S (eds) (2005) Person Centred Planning and Care Management with People with Learning Disabilities . London: Jessica Kingsley

British Psychological Society (2000) Learning Disability: Definitions and Contexts. Leicester: BPS

Craven, A \& Potter J (2010) Directives: Contingency and entitlement in action, Discourse Studies, 12, 1-24

Curl, T. S., Drew, P (2008) Contingency and action: a comparison of two forms of requesting, Research on Language \& Social Interaction, 41/2: 129-53 
Department of Health (2001). Valuing people: A new strategy for learning disability for the 21st century. London: HMSO.

Department of Health (2009) Valuing People Now: a new three-year strategy for people with learning disabilities. In: Making it Happen for Everyone, (ed. Department of Health), London. Available at: http://webarchive.nationalarchives.gov.uk/20130107105354/http://www.dh.g ov.uk/prod_consum_dh/groups/dh_digitalassets/documents/digitalasset/dh_09 3375.pdf [Accessed 23 March 2015]

Finlay, W.M.L., Walton, C. \& Antaki, C. (2008). A manifesto for the use of video in service improvement and staff development in residential services for people with learning disabilities. British Journal of Learning Disabilities. 36, 227-231

Heritage, J. (2012) 'The epistemic engine: Sequence organization and territories of knowledge', Research on Language \& Social Interaction 45/1: 30-52

Johnson, K (2013) The UN Convention on the Rights of Persons with Disabilities: A Framework for Ethical and Inclusive Practice? Ethics and Social Welfare, 7, 218-231

MENCAP (no date) Independent Living. https://www.mencap.org.uk/getinvolved/campaigns/what-we-campaign-about/independent-living [accessed March 22nd 2015]

Mühlhäusler, P. and Harré, R. (1990). Pronouns and People: The Linguistic Construction of Social and Personal Identity. Oxford: Basil Blackwell.

Power, A (2011) Understanding the complex negotiations in fulfilling the right to independent living for disabled people. Disability and Society, 28, 204-217

Rapley. M (2004) The social construction of Intellectual disability. Cambridge, England: Cambridge University Press. 
Routledge, M. \& Sanderson, H. (2001). Planning with people: towards personcentred approaches. Guidance for Implementation Groups. Department of Health; London

Scottish Government (2014) Self-Directed Support: National Guides http://guidance.selfdirectedsupportscotland.org.uk/ [Accessed 23 March 2015]

Sempik, J., Aldridge, J. \& Becker, S. (2005), Health, Well-being and Social Inclusion: Therapeutic Horticulture in the UK. Bristol: The Policy Press.

Shakespeare, T (2nd ed., 2014) Disability Rights and Wrongs . Abingdon: Routledge

Simson, S. \& Straus, M. C. (2003) Horticulture as therapy: principles and practice Abingdon: Routledge.

Stevanovic M. and Svennevig J. (in press 2015) Introduction: epistemics and deontics in conversational directives. Journal of Pragmatics, $\mathrm{xx}, \mathrm{xx}-\mathrm{xx}$

Tassé, M.J, Schalock R.L, Balboni, G, Bersani, H. Jr, Borthwick-Duffy, S.A. , Spreat, S, Thissen, D., Widaman, K F. \& Zhang, D (2012) The Construct of Adaptive Behavior: Its Conceptualization, Measurement, and Use in the Field of Intellectual Disability. American Journal on Intellectual and Developmental Disabilities: July 2012, Vol. 117, No. 4, pp. 291-303.

United Nations. 2006. Convention on the Rights of Persons with Disabilities. UN General Assembly adopted by consensus the Convention on the Rights of Persons with Disabilities and its Optional Protocol 13 Dec. 2006 (New York) http://www.un.org/disabilities/default.asp?id=150 [Accessed March 22nd 2015] 
Wehmeyer, M. L. \& Bolding N. (2001) Enhanced self-determination of adults with intellectual disability as an outcome of moving to community-based work or living environments . Journal of Intellectual Disability, 45, 371-383

Williams, V (2011) Disability and Discourse Chichester: Wiley-Blackwell 
$\underline{\text { Authors' bios }}$

Charles Antaki is Professor of Language and Social Psychology at Loughborough University, in the Department of Social Sciences. His research interests are in Conversation Analysis, and among his publications is the edited collection Applied Conversation Analysis: Intervention and Change in Institutional Talk (Palgrave Macmillan, 2011).

Rebecca J. Crompton graduated with a BSc in Social Psychology (first class) from Loughborough University. She has written for the British Psychological Society publication PsyPag and is currently working as a Learning Support Assistant at a mainstream secondary school. 